\title{
Numerical Investigation Of Heat Transfer in a Multi-Layer Wall Used in Brazilian Buildings
}

\author{
Pedro Felipe Lavra Dias ${ }^{1}$, Lourival Matos de Sousa Filho ${ }^{1}$, William Denner Pires Fonseca ${ }^{2}$ \\ ${ }^{1}$ Center of Technological Sciences - UEMA, State University of Maranhão \\ São Luis, Brazil \\ pedrodias@aluno.uema.br; lourivalfilho@professor.uema.br \\ ${ }^{2}$ University of Campinas \\ Campinas, Brazil
}

\begin{abstract}
This paper investigates thermal walls behavior as elements of buildings and low-consumption energy residences. The problem is formulate based on the transient and unidimensional model, and numerically solved using the finite volumes method to discretize space and the implicit formulation to discretize time. Numerical tests were realized to optimize the mesh. Three different materials, heat transfer coefficient and color incorporation were tested in each wall layer A and B. The influence of these variations in the internal wall was calculated for each case. It was found that the best material for A and B walls are plaster mortar and common brick, respectively. This is a result of the inverse correlation between thermal resistance and the heat transfer rate. For a lower temperature in the external and internal walls, the thickness ratio for the external wall was $\beta<0.5$ and for the inner wall was $\beta>$ 0.5 . The best value of absorptivity was 0.156 and the external heat transfer coefficient was variated to increase heat change. With all these parameters analyzed, it was possible to decrease significantly the heat transfer to the inner space and enhance the thermal comfort.
\end{abstract}

Keywords: Thermal Walls, Finite Volumes Method, Implicit Formulation, Thermal Comfort.

\section{Introduction}

Due high - velocity winds, heavy rains and elevated solar radiation, Brazilian summer presents a tough challenge for buildings thermal insulation [1]. Generally speaking, 30\% - 50\% of energy bills comes from thermal maintenance [2]. This commonly aggravates electricity peak demand problems at some hours of a day since $90 \%$ of Brazilian electricity comes from hydroelectric and thermoelectric stations, which totally affect environmental conditions - $\mathrm{CO} 2$ and $\mathrm{CH} 4$ emissions [3-4].

In order to decrease or eliminate this problem, different materials and their proportions into a multi-layer wall were compared. Isa et al. [5] affirms that increasing the thermal storage capacity of any construction may enhance human comfort, this way, Common Brick, Concrete block, Clay tile as inner layer and the mixtures gypsum plaster with sand aggregate, gypsum plaster with vermiculite and plaster mortar as external layer were tested.

The literature is rich with researches in this area. Applying finite differences technique Avila and Ismail [6] analyzed the behavior of insulation walls in low energy consumption buildings; using the same method Aydin [7] numerically investigated the effect of air layer into a double pane window. Lacarrière et al. [8], experimentally working with vertically perforated bricks, also researched about unsteady heat transfer in a multi- layer wall with air layer.

According to Manjoglu and Yilmaz [9], the main parameter that interferes in a multi-layer thermal efficiency is the wrapping material. Santamouris et al. [10] affirms that high reflective plasters are the best way to decrease internal temperatures of buildings.

To calculate the heat gain/loss through walls requires solving the unsteady and high order heat-conduction differential equation with transient boundary conditions. [11-12]. Armando et al. [13], analyzed the conjugate heat transfer in a multilayer furnace wall, using computational fluid dynamics (CFD).

A common subject in multi-layer wall study is phase change material. These types of walls are made of a material, with suitable phase change temperature, between two general layers [14-16]. Bernard et al. [17] realized an investigation on PCM walls composed of a double-glass window, a gap for controlled air circulation and an internal paraffin wall. 
Another research area is the application of life cycle assessment (LCA) to external wall insulation materials. This way Danielle et al. [18] has compared the environmental impact of three insulation materials. Ingrao et al. [19] used an LCA study with recycled PET bottles as insulation panels.

\section{Mathematical Formulation and Numerical Method}

\subsection{Mathematical Modelling}

The sketch of the problem is shown in Figure 1. The energy equation modulated the problem in the unidimensional $-\mathrm{x}$ direction, conservative, transient, without heat generation and constant properties form. The room side has a constant convection heat transfer coefficient and temperature, the external wall receives solar radiation varying with time and also a constant convection heat transfer coefficient different of the first one. Considering the above simplifications, the temperature field can be described as the Equation 1.

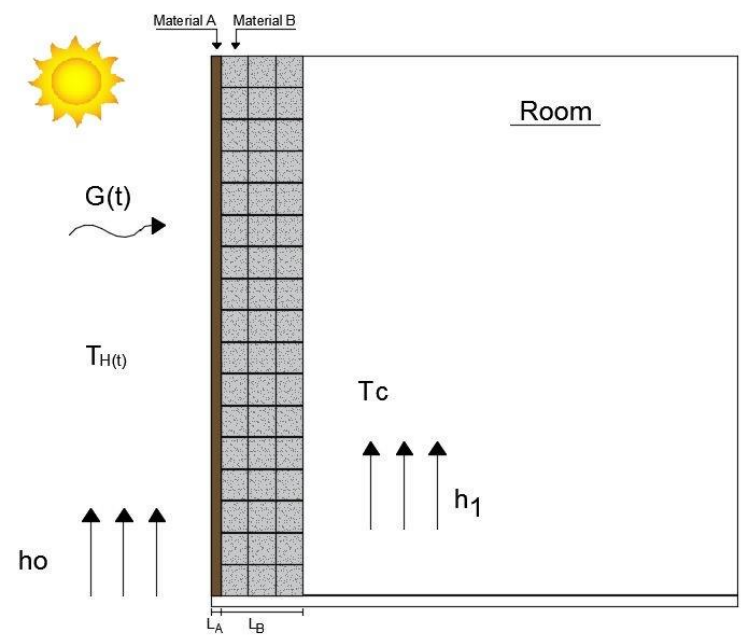

Fig. 1: Geometric details of the investigated thermal walls.

(i) Energy equation:

$$
\frac{\partial T_{A, B}}{\partial t}=\alpha_{A, B}\left[\frac{\partial}{\partial x_{A, B}}\left(\frac{\partial T_{A, B}}{\partial x_{A, B}}\right)\right] \quad \begin{aligned}
& 0<x_{A}<L_{A} \\
& L_{A}<x_{B}<L_{B}
\end{aligned}
$$

Where A and B are the multi-layer wall materials, with the boundary conditions as shown in Eqs. (2) - (4):

(ii) External wall:

$$
-k_{A} \frac{\partial T_{A}}{\partial x_{A}}=h_{o}\left(T_{H}(t)-T\right)+\alpha_{a b s v} G(t) \quad x_{A}=0, \mathrm{t}>0
$$

(iii) Interface:

$$
\begin{aligned}
& T_{A}=T_{B} \\
& -k_{A} \frac{\partial T_{A}}{\partial x_{A}}=-k_{B} \frac{\partial T_{B}}{\partial x_{B}} \quad x_{A}=x_{B}=L_{A}, \mathrm{t}>0
\end{aligned}
$$


(iv) Internal wall:

$$
-k_{B} \frac{\partial T_{B}}{\partial x_{B}}=h_{1}\left(T-T_{C}\right) \quad x_{B}=L_{B}, \mathrm{t}>0
$$

$\mathrm{G}(\mathrm{t})$ is the incident solar radiation and $T_{H}(t)$ is the environment temperature, both time dependent. These data were published by INMET - national institute of meteorology - website for São Luís, Maranhão - Brazil summer (December).

\subsection{Numerical Method}

In order to solve the governing equation and the boundary conditions, the finite volumes method and the implicit formulation were used to discretize Eqs. (1) - (4). A numerical program was developed with a optimazed - 40 volumes numerical mesh, Figure 2. It was simulated with a $\Delta \tau=0.01 \mathrm{~s}$ and $0.1 \mathrm{~s}$ time-step, choosing $\Delta \tau=0.1$, Figure 3 , since the lower computational effort.

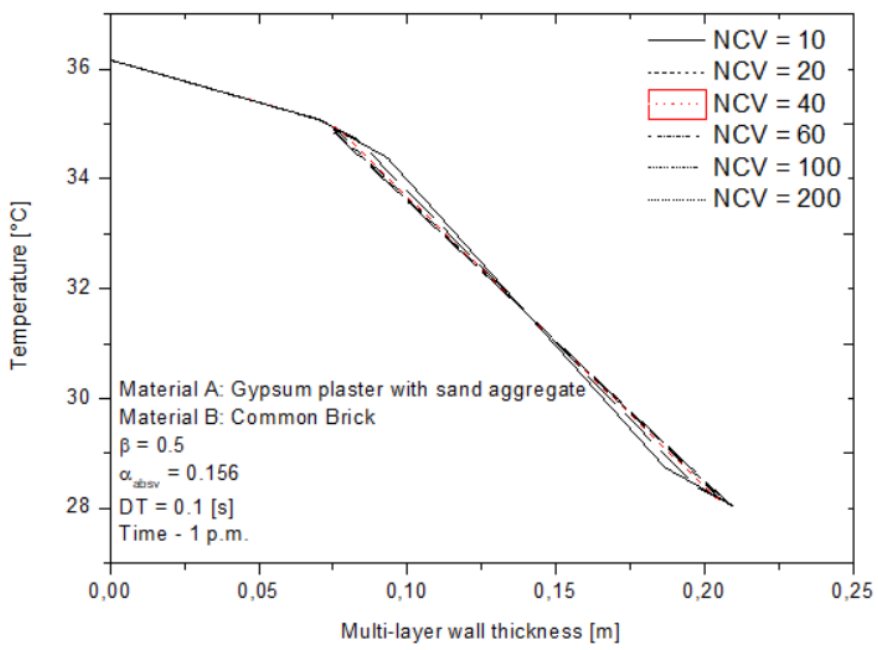

Fig. 2: Optimized computational mesh.

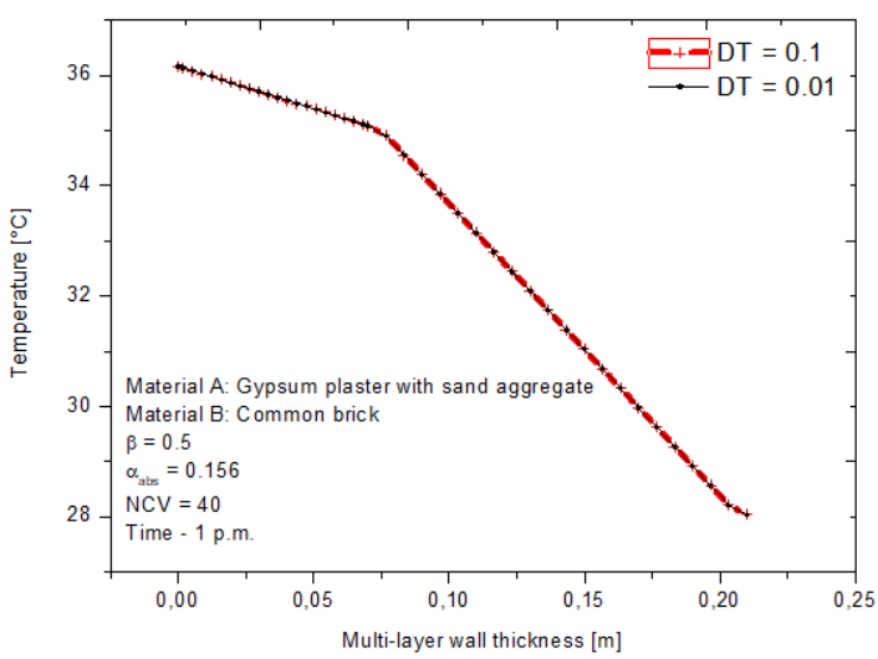

Fig. 3: Optimized time step. 


\section{Results and Discussion}

A large number of numerical simulations is performed in the thermal walls to investigate the effects of thickness ratio, thermal properties of locally used materials, external convective heat transfer coefficient and external wall finish and color. The meteorological data of solar radiation is inherent of São Luís, Brazil and the room heat transfer coefficient is 6,0 W / $\mathrm{m}^{2}$. K. All results were simulated for 1 p.m., since it has the maximum solar radiation. B layer has 0.14 m thickness.

\subsection{Effect of Construction Materials Thermal Conductivity}

The simulations were performed to investigate the effect of construction materials thermal conductivity. In order to obtain the lower temperature in both walls it was varied three materials in the external and internal walls where could be seen that plaster mortar as material A and common brick as material B presented the bests results in heat comfort maintenance. Figures $4-6$ present these results.

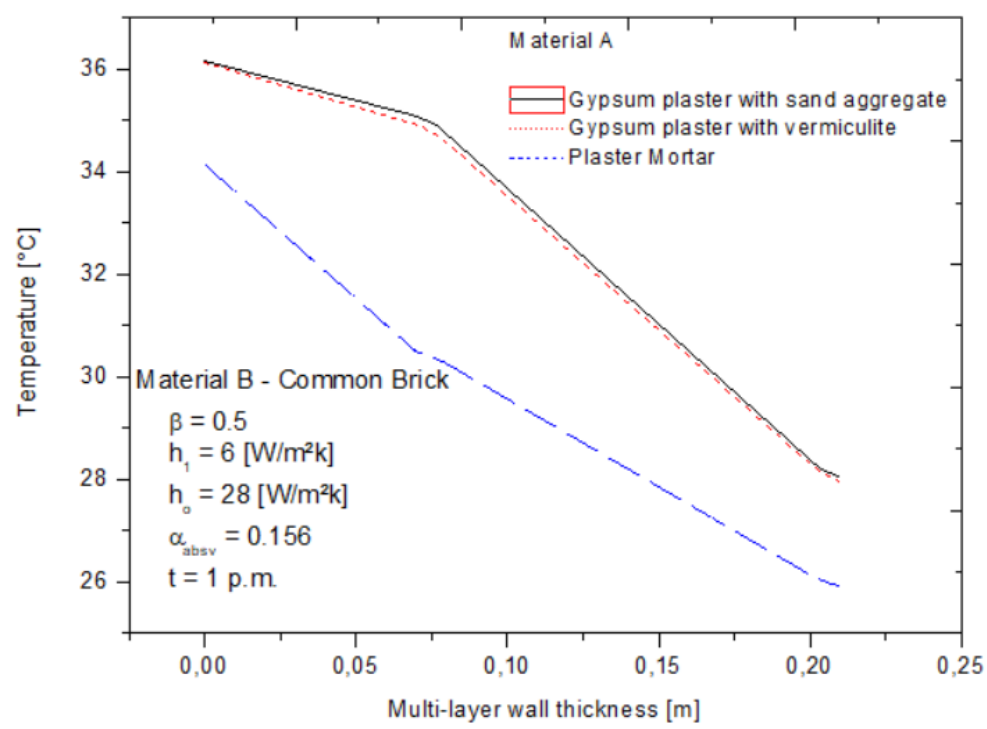

Fig. 4: Influence of material A on external and internal wall temperature - material B: common brick.

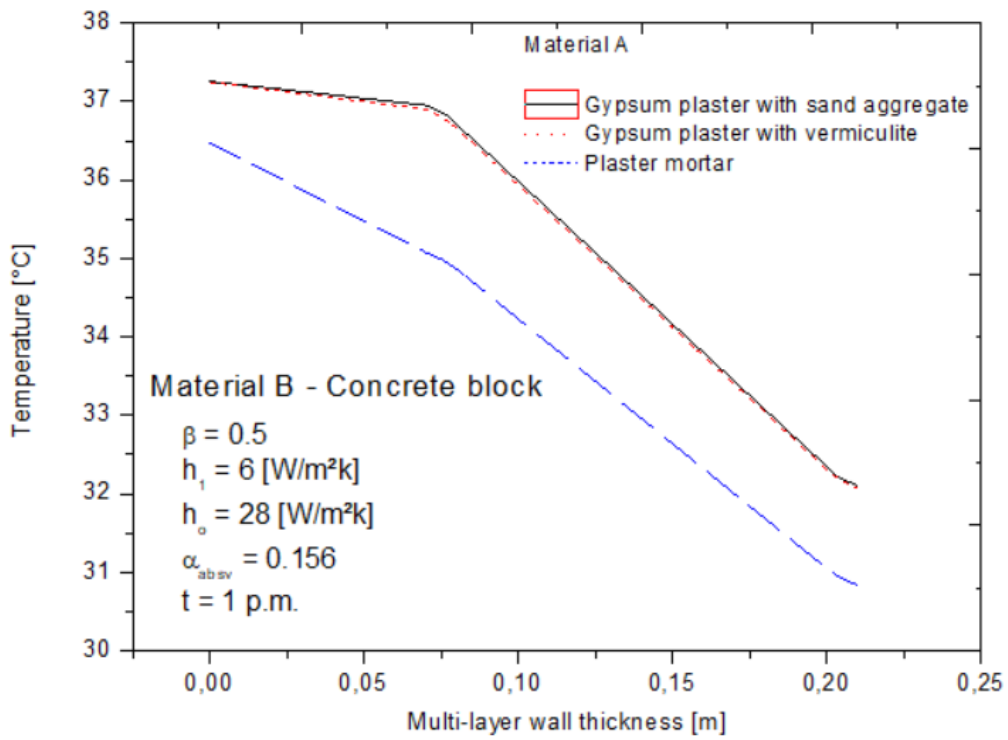

Fig. 5: Influence of material A on external and internal wall temperature - material B: Concrete block. 


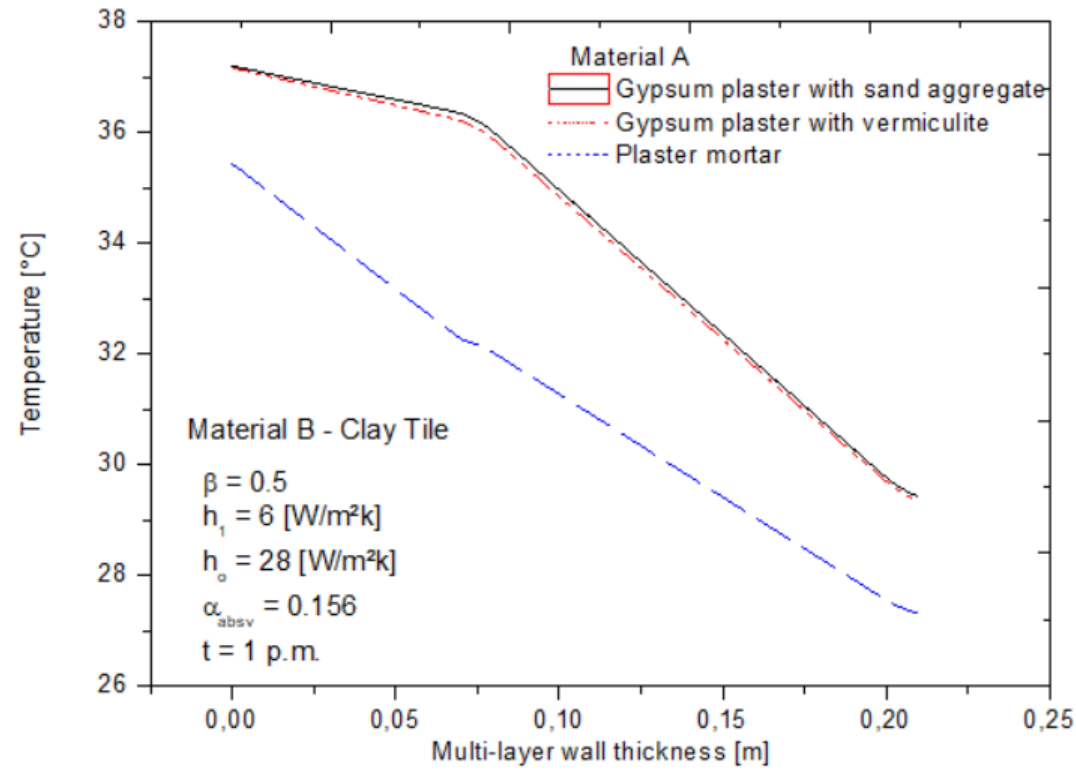

Fig. 6: Influence of material A on external and internal wall temperature - material B: Clay tile.

\subsection{Effect of External Wall Thickness}

The effect of external wall thickness, called thickness $\beta$, expressed by Figs. $7-8$, is the one which increasing $\beta$, the external wall temperature also increases and the internal wall temperature decreases. This happens because as the thermal resistance enhances, the heat transfer ratio gets lower.

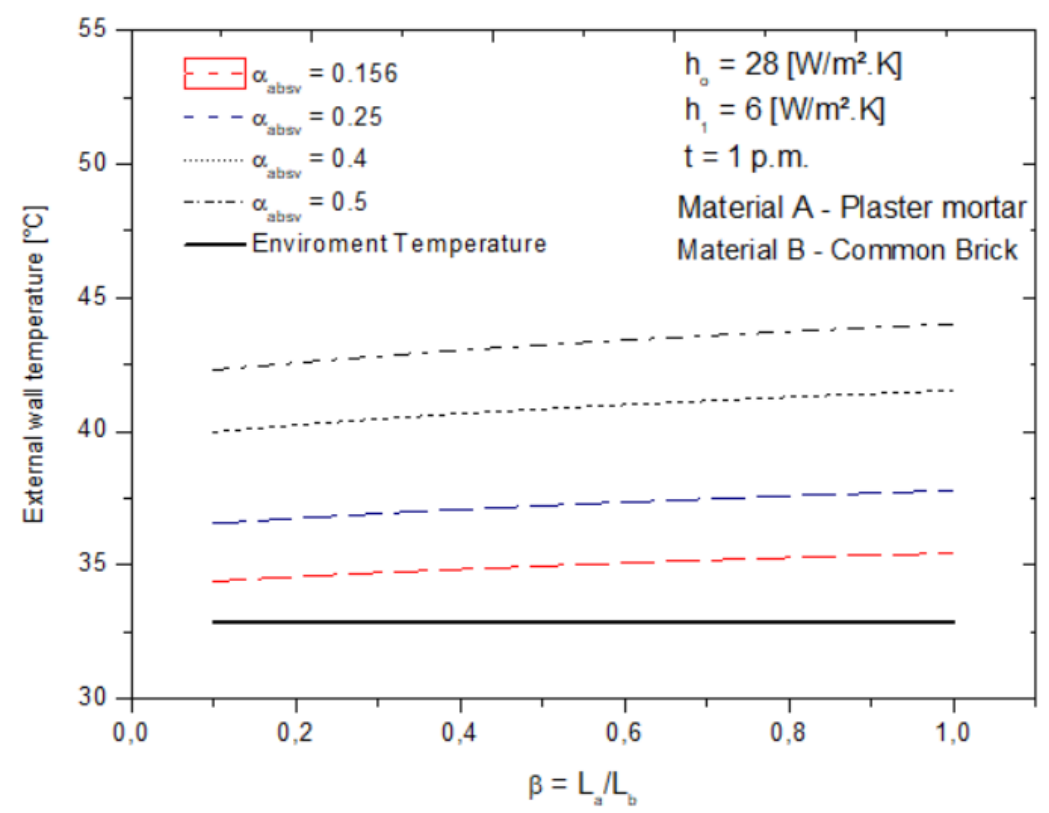

Fig. 7: Effect of material thickness A on external wall temperature, for different absorptivity. 


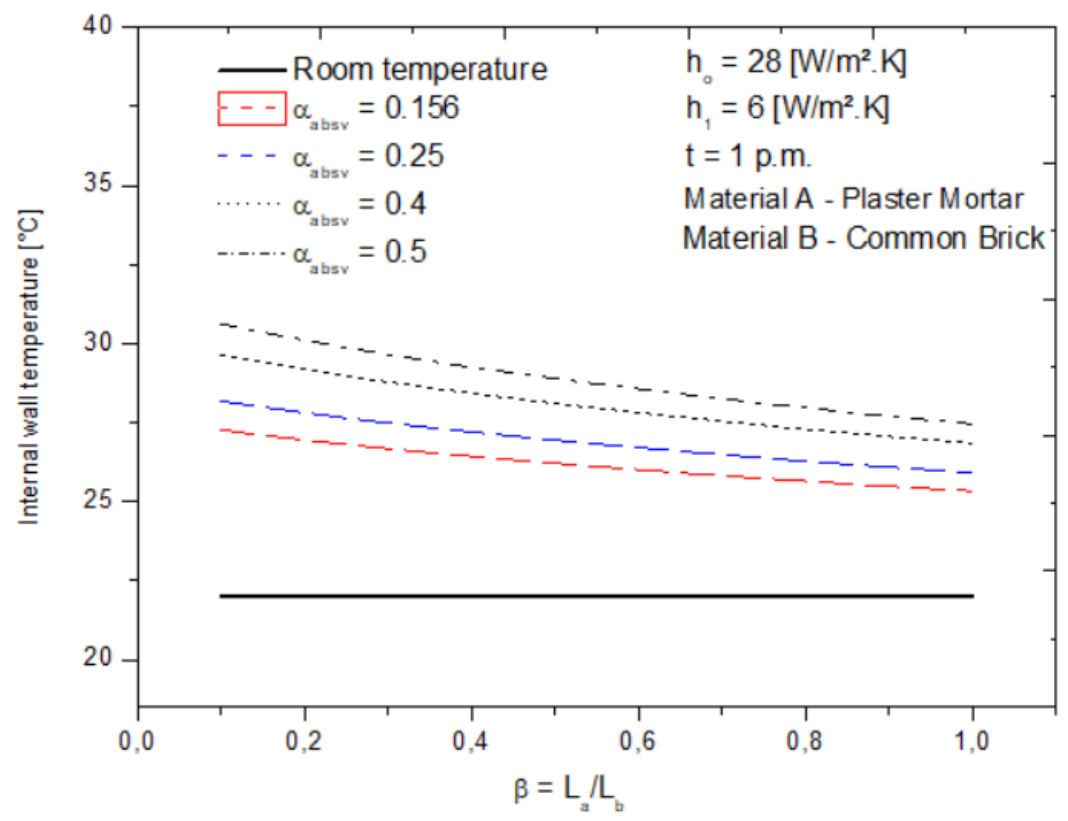

Fig. 8: Effect of material thickness A on internal wall temperature, for different absorptivity.

\subsection{Effect of the External Heat Transfer Coefficient}

Figs. 9 - 10 illustrate the influence of heat transfer coefficient in the external and internal walls temperatures. The bigger the heat transfer coefficient is (higher winds velocity), the smaller the walls temperature is.

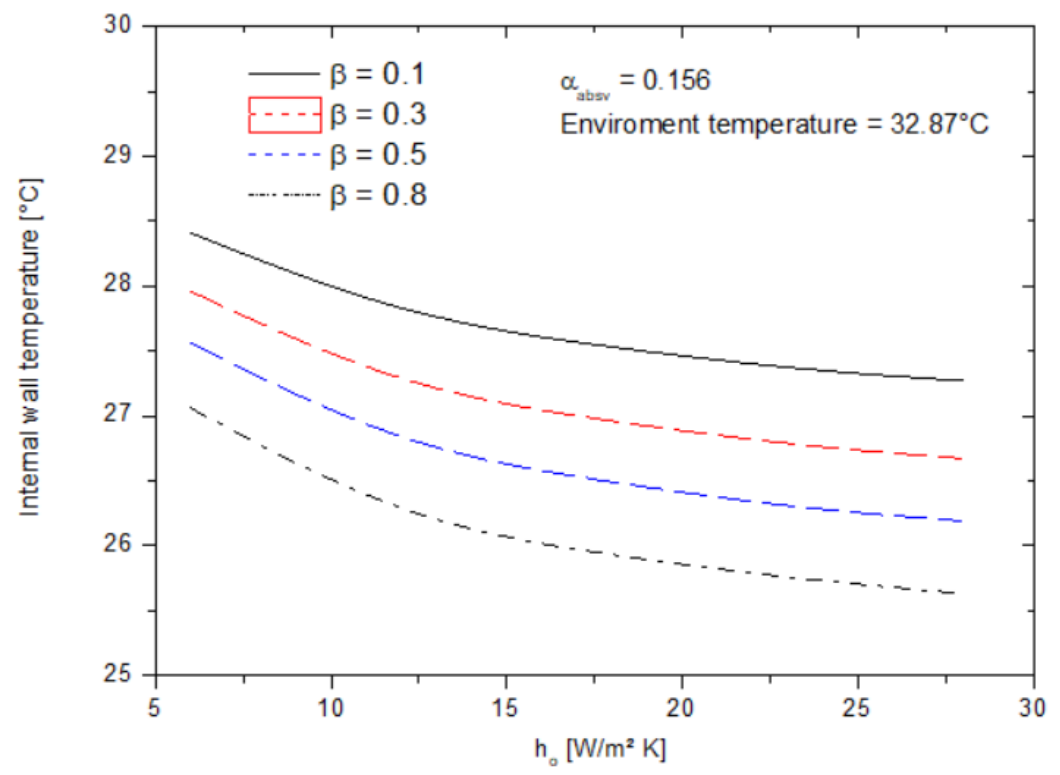

Fig. 9: Effect of heat transfer coefficient on internal wall temperature for different $\beta$. 


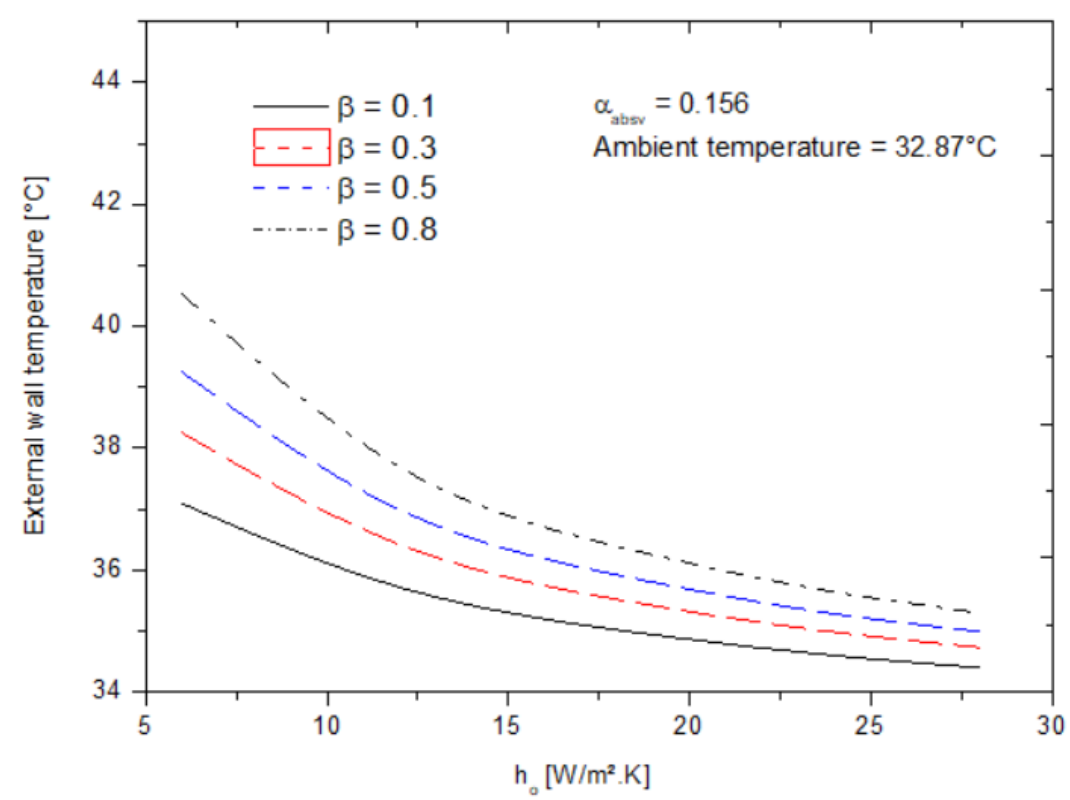

Fig. 10: Effect of heat transfer coefficient on external wall temperature for different $\beta$.

\section{Conclusion}

As was said, three materials for the two walls were investigated, the mixtures gypsum plaster with sand aggregate, gypsum plaster with vermiculite and plaster mortar as the A wall and Common Brick, Concrete block, Clay tile as the B wall. For the purposed problem, the materials plaster mortar - external wall - and common brick - internal wall presented the lower temperature on the room side. This is a good result since most of the Brazilian buildings are made of these both materials.

Another parameter analyzed was the variation of the wall thickness, this way it is correct to affirm that when the two layers have the same thickness, in other words, when $\beta=1,0$ the inside wall temperature is lower. It is obvious since the total thermal resistance is a function of the thickness of materials.

As it is known, the absorptivity depends on the nature of the radiation as well as on the surface finishing details. Besides that, the bigger is the absorptivity the larger is the thermal energy of the material. In this way, the proper coefficient value is 0.156 which is the lower allowed for the plaster mortar.

According to what was exposed, the better choice of the materials in a construction is fundamental for the thermal comfort of the buildings' parts. Specifically speaking, in the northeast of Brazil which high temperatures are measure throughout the year, it is extremely important to apply this knowledge for the thermal maintenance and, of course, for the energy consumption saving.

\section{Acknowledgements}

The authors wish to acknowledge the Laboratory of Modeling and Simulation - MSiLAB/UEMA - for infrastructure, FAPEMA and Cnpq for financial support.

\section{References}

[1] J. Tamdjian and I. Lazzari, Geografia estudos para compreensão do espaço. São Paulo, SP: FTD, 2013.

[2] P. L. Lombard, J. Ortiz, C. Pout, "A review on buildings energy consumption information," Energy Build, vol. 40, pp. 394-398.

[3] E. Alabi Lucci, A. Lazaro Branco, C. Mendonça, Território e sociedade no mundo globalizado. São Paulo, SP: Saraiva, 2010.

[4] P. Fearnsid, (2017, January 29), Dams with big reservoirs. [Online]. Available: https://www.internationalrivers.org 
[5] M. Isa, X. Zhao and H. Yoshino, "Preliminary Study of Passive Cooling Strategy Using a Combination of PCM and Copper Foam to Increase Thermal Heat Storage in Building Façade,” Sustainability, pp. 2365-2381, 2010.

[6] J. Avila, K. Ismail, "Composite Thermal Walls for Low Energy Brazilian Homes," in $13^{\text {th }}$ International Conference on Heat Transfer, Fluid Mechanics and Thermodynamics, Campinas, SP.

[7] O. Aydin, "Conjugate Heat Transfer Analysis of Double Pane Windows," Building and Environment, vol. 41, pp. 109-116, 2005.

[8] B. Lacarrière, A. Trombe, F. Monchoux, "Experimental Unsteady Characterization of Heat Transfer in a Multi-layer Wall Including Air Layers - Application to Vertically Perforated Bricks," Energy and Buildings, vol. 38, pp. 232237, 2005.

[9] G. Manioglu, Z. Yilmaz, "Economic evaluation of the building envelope and operation period of heating system in terms of thermal comfort," in Energy and Buildings, vol. 38, no. 3, pp. 266-272, 2006.

[10] M. Santamouris; K. Pavlou; A. Synnefa; K. Niachou; D. Kolokotsa, "Recent progress on passive cooling techniques - Advanced technological developments to improve survivability levels in low-income households," in Energy and Buildings, vol. 39, no. 7, pp.859-866, 2007.

[11] E. Wang, W. Liu, "Unsteady Heat Transfers through a Multi-layer Wall," Applied Energy, vol. 31, pp. 83-99, 1988.

[12] W. Liu, E. Wang, "Heat Transfer Behavior of Thermally Insulated and Uninsulated Buildings," Applied Energy, in press.

[13] G. Armando, B. Armando, V. Christian, R. Hernández, J. Flores, "Analysis of the Conjugate Heat Transfer in a Multi-layer Wall Including an Air Layer," Applied Thermal Engineering, vol. 30, pp. 599-604, 2010.

[14] A. Gounni, M. Alami, "The Optimal Allocation of the PCM within a Composite Wall for Surface Temperature and Heat Flux Reduction: An Experimental Approach,” Applied Thermal Engineering, vol. 127, pp. 1488-1494, 2017.

[15] K. Roth, D. Westphalen, J. Brodrick, "PCM Technology for Building Materials," ASHRAE J., 2007.

[16] K. Ismail, J. Castro, "PCM Thermal Insulation in Buildings," International Journal of Energy Research, vol. 21, pp. 1281-1296, 1997.

[17] C. Benard, Y. Gobin, B. Guerrier, "Use of a Variable Parameter Test-cell for the Study of Latent-het Solar Walls," Solar Energy, vol. 29, pp. 101-109, 1982.

[18] D. Densley Tingley, A. Hathway, B. Davison, "An environmental impact comparison of external wall insulation," Building and Environment, vol. 85, pp. 182-189, 2015.

[19] C. Ingrao, A. Lo Giudice, C. Tricase, C. Rana, V. Siracusa, "Recycled -PET fibre based panels for building termal insulation: environmental impact and improvement potential assesment for a greener production," Sci Total Environ, pp. 914-929, 2014. 